\section{Commentary: Following the game-changers: Are we on the right track now?}

\author{
Song Wan, MD, FRCS, ${ }^{a}$ and Jia $\mathrm{Hu}, \mathrm{MD}, \mathrm{PhD}^{\mathrm{b}}$
}

Over the past few years, there have been many heated discussions about selecting the appropriate surgical strategy for ischemic mitral regurgitation (IMR) during coronary artery bypass grafting procedures. The initial results of the Cardiothoracic Surgical Trials Network (CTSN) multicenter randomized investigations on severe and moderate IMR were published in January and December 2014, respectively. ${ }^{1,2}$ Their subsequent 2 -year follow-up findings were reported in 2016, again in the New England Journal of Medicine. ${ }^{3,4}$ These 4 articles generated intense debate among the cardiac surgical community worldwide and eventually became authentic game-changers. In 2017, the American Heart Association/American College of Cardiology guidelines were modified accordingly. ${ }^{5}$ For severe IMR, replacement of the mitral valve with a chordal-sparing technique was considered more reliable than downsized annuloplasty; for moderate IMR, simply leaving it alone is no longer considered a bad choice, because "the usefulness of mitral valve repair is uncertain." 5 To some surgeons, the decision making process appears easier today. However, in terms of clinical outcomes, whether we are making any substantial progress by implementing such a "simplified" surgical policy remains uncertain.

To address this question, Nappi and colleagues ${ }^{6}$ have conducted a timely meta-analysis. Along with analyzing the available surgical trials, their comprehensive systematic

From the a Division of Cardiothoracic Surgery, Department of Surgery, The Chinese University of Hong Kong, Prince of Wales Hospital, Hong Kong; and ${ }^{\mathrm{b}}$ Department of Cardiovascular Surgery, West China Hospital, Sichuan University, Chengdu, China.

Disclosures: The authors reported no conflicts of interest.

The Journal policy requires editors and reviewers to disclose conflicts of interest and to decline handling or reviewing manuscripts for which they may have a conflict of interest. The editors and reviewers of this article have no conflicts of interest.

Received for publication June 16, 2020; accepted for publication June 16, 2020; available ahead of print June 29, 2020.

Address for reprints: Song Wan, MD, FRCS, Division of Cardiothoracic Surgery, Department of Surgery, The Chinese University of Hong Kong, Prince of Wales Hospital, Hong Kong, China (E-mail: swan@surgery.cuhk.edu.hk).

J Thorac Cardiovasc Surg 2022;163:624-5

$0022-5223 / \$ 36.00$

Copyright (c) 2020 by The American Association for Thoracic Surgery

https://doi.org/10.1016/j.jtcvs.2020.06.070

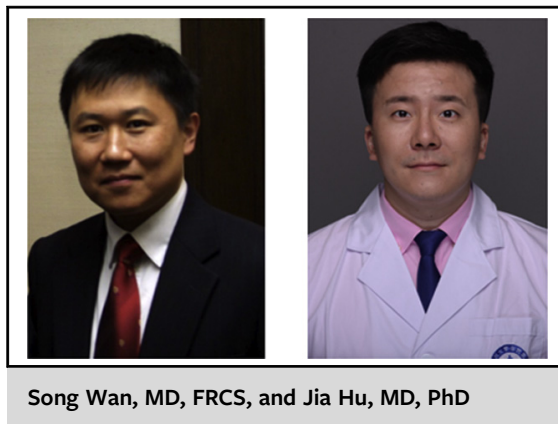

CENTRAL MESSAGE

Repair as the principle is not inappropriate for treating ischemic mitral regurgitation, despite restrictive annuloplasty may not always be a winner. The real issue is, we must do the right repair for the right patient.

review also covers several important aspects, including rapidly-evolving transcatheter therapy-namely, the MitraClip intervention-and the latest clinical evidence on guideline-directed medical therapy. The former was highlighted by 2 recent multicenter randomized trials: the Percutaneous Repair with the MitraClip Device for Severe Functional/Secondary Mitral Regurgitation (MITRA-FR) ${ }^{7}$ and Cardiovascular Outcomes Assessment of the MitraClip Percutaneous Therapy for Heart Failure Patients with Functional Mitral Regurgitation $(\text { COAPT })^{8}$ studies. Even though neither trial included a surgical arm for a broader comparison, they are arguably considered by many to be game-changers as well. Such updated information is definitely noteworthy; however, in this brief commentary, we focus only on 2 fundamental surgical issues-selecting the right patients and applying the right techniques.

The first issue relates to patient selection. Few would disagree that it is illogical to choose replacement strategy over repair in the setting of IMR. IMR is a ventricular problem, not a valvular problem. The mitral valve is basically normal, which is why IMR is classified as "functional." It makes little sense to routinely replace a normal valve with an artificial prosthesis.

So what have we truly learned from the 2 important CTSN trials? On the one hand, we recognize that patients who had severe IMR following successful downsized annuloplasty (ie, without recurrence of MR) had the best 

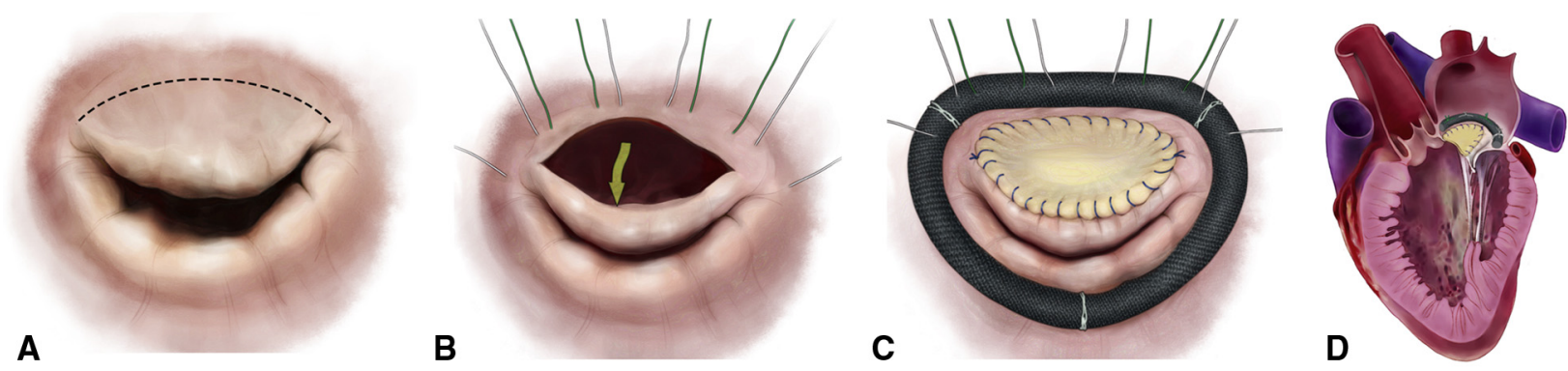

FIGURE 1. Anterior mitral valve leaflet patch augmentation with true-sized annuloplasty. A, After the true-size annular measurement according to the usual principle (ie, based on the size of the anterior leaflet and on the intertrigonal distance), an incision is made along the anterior mitral annulus (the dashed line). B and C, A CardioCel (LeMaitre Vascular, Burlington, Mass) patch slightly larger than the space area succeeding the "fall" of the anterior mitral leaflet is prepared and sutured on the leaflet, followed by a true-sized semirigid ring annuloplasty. $\mathrm{D}$, Systolic anterior motion is never a concern, as the patch-augmented anterior mitral valve leaflet is always "pushed" toward the left atrium during the systolic phase.

clinical outcomes. ${ }^{1,3,6}$ The well-proven principle "good repair is always better than good replacement" remains valid. Thus, restrictive annuloplasty as a useful tool could still be applied in some carefully selected patients. On the other hand, the disappointing high incidence of MR recurrence- $58.8 \%$ at a 2-year postoperative follow-up in the CTSN severe IMR trial ${ }^{3}$-reflects the failure of restrictive annuloplasty in another subgroup of patients. Nonetheless, it does not instinctively indicate the overall "failure of mitral valve repair." The challenge facing us now is to reliably identify this specific patient subgroup (in whom restrictive annuloplasty may not work) before surgical intervention. In fact, the CTSN investigators ${ }^{9}$ recently discovered a crucial criterion: left ventricular (LV) size. They showed that the mismatch between LV size and mitral ring size is an independent predictor of recurrent MR after restrictive annuloplasty. ${ }^{9}$ In other words, downsized annuloplasty is likely to fail in patients with severe IMR who have a significantly enlarged LV.

Equally important is the second issue that relates to the surgical strategy. A revolutionary concept modification is to apply true-sized annuloplasty in cases with enlarged LV (which resulted from the adverse remodeling secondary to myocardial infarction). For instance, in terms of preventing postoperative recurrent MR, a mitral annuloplasty ring size of $32 \mathrm{~mm}$ would be better than $26 \mathrm{~mm}$ if the LV end-systolic dimension was $52 \mathrm{~mm} .{ }^{9}$ Regarding the ring choice, we now prefer to use complete (rather than C-shaped band), semirigid (rather than rigid) rings in the IMR setting. ${ }^{10}$ As the primary goal of the mitral valve repair is to restore an optimal surface of coaptation, some additional repair techniques besides the annuloplasty are definitely needed. Nappi and colleagues summarize the possible contributions of the subannular repair techniques. Over the past few years, we have chosen to perform anterior mitral valve leaflet patch augmentation plus true-sized annuloplasty (Figure 1) and have observed satisfactory short- and mid-term clinical results.

In summary, we strongly believe that compared with mitral valve replacement or MitraClip intervention in the setting of moderate to severe IMR, mitral valve repair using appropriate surgical strategy and guideline-directed medical therapy can further improve the clinical outcomes in carefully selected patients. Future multicenter randomized evaluations are warranted when we truly do what is right, not what is easy or popular.

\section{References}

1. Acker MA, Parides MK, Perrault LP, Moskowitz AJ, Gelijns AC, Voisine P, et al Mitral valve repair versus replacement for severe ischemic mitral regurgitation. $N$ Engl J Med. 2014:370:23-32.

2. Smith PK, Puskas JD, Ascheim DD, Voisine P, Gelijns AC, Moskowitz AJ, et al. Surgical treatment of moderate ischemic mitral regurgitation. $N$ Engl J Med. 2014;371:2178-88

3. Goldstein D, Moskowitz AJ, Gelijns AC, Ailawadi G, Parides MK, Perrault LP, et al. Two-year outcomes of surgical treatment of severe ischemic mitral regurgitation. N Engl J Med. 2016;374:344-53.

4. Michler RE, Smith PK, Parides MK, Ailawadi G, Thourani V, Moskowitz AJ, et al. Two-year outcomes of surgical treatment of moderate ischemic mitral regurgitation. $N$ Engl J Med. 2016;374:1932-41.

5. Nishimura RA, Otto CM, Bonow RO, Carabello BA, Erwin JP III, Fleisher LA, et al. 2017 AHA/ACC focused update of the 2014 AHA/ACC guideline for the management of patients with valvular heart disease: a report of the American College of Cardiology/American Heart Association task force on clinical practice guidelines. Circulation. 2017;135:e1159-95.

6. Nappi F, Antoniou GA, Nenna A, Michler R, Benedetto U, Avtaar Singh SS, et al. Treatment options for ischemic mitral regurgitation: a meta-analysis. $J$ Thorac Cardiovasc Surg. 2022;163:607-22.e14.

7. Obadia JF, Messika-Zeitoun D, Leurent G, Iung B, Bonnet G, Piriou N, et al. Percutaneous repair or medical treatment for secondary mitral regurgitation. $N$ Engl J Med. 2018;379:2297-306.

8. Stone GW, Lindenfeld J, Abraham WT, Kar S, Lim DS, Mishell JM, et al. Transcatheter mitral-valve repair in patients with heart failure. N Engl J Med. 2018; 379:2307-18.

9. Capoulade R, Zeng X, Overbey JR, Ailawadi G, Alexander JH, Ascheim D, et al Impact of left ventricular to mitral valve ring mismatch on recurrent ischemic mitral regurgitation after ring annuloplasty. Circulation. 2016;134: $1247-56$.

10. Wan S, Lee AP, Jin CN, Wong RH, Chan HH, Ng CS, et al. The choice of mitral annuloplastic ring-beyond "surgeon's preference". Ann Cardiothorac Surg. 2015;4:261-5. 